\title{
Design and Implementation of Women Safety System
}

\section{S Venkata Lakshmi ${ }^{1}$ | Prathiban $^{2}$ | Praveen Kumar ${ }^{2}$}

\begin{abstract}
${ }^{1}$ Assistant Professor, Department of computer science and Engineering, K.L.N. College of Engineering. Sivagangai, TamilNadu, India

${ }^{2}$ Student, Department of computer science and Engineering, K.L.N. College of Engineering. Sivagangai, TamilNadu, India
\end{abstract}

To Cite this Article

S Venkata Lakshmi, Prathiban and Praveen Kumar, "Design and Implementation of Women Safety System", International Journal for Modern Trends in Science and Technology, Vol. 06, Issue 06, June 2020, pp.:186-190; https://doi.org/10.46501/IJMTST060634

\section{Article Info}

Received on 26-May-2020, Revised on 05-June-2020, Accepted on 13-June-2020, Published on 25-June-2020.

\section{ABSTRACT}

In this paper it is proposed to have a device which is the integration of multiple devices, hardware comprises of a wearable "Smart gadget" which continuously communicates with Smart phone that has access to the internet. The complete gadget also ensures to provide self-defence application which helps her to escape critical situations. This system can be used at places like bus stops, railway stations, offices, footpaths, shopping malls, markets, etc. The implementation of the smart gadget is basically split into two sections the first part ensures to pulse of the person. The device get automatically triggered when there is a suspected increase in pulse of the person, the device sends a message to the respective persons like parents, friends with the location of the Victim. The second section deals with the turning on of the button by pressing it by victim. If she is in danger, then the device will get automatically triggered and sends a message to the parents or friends with their location in map.If the device got broken then the notification will be send to the respective persons about device status. It ensures them to change the device.

KEYWORDS: SHE, ILA Security, Aeshs

Copyright (C) 2014-2020 International Journal for Modern Trends in Science and Technology

DOI: $\underline{\text { https://doi.org/10.46501/IJMTST060634 }}$

\section{INTRODUCTION}

Women are the backbone of any economy primarily shaping future of the country. She who earlier stayed at home to attend her domestic duties is now maintaining work and home simultaneously, participating in the process of economic development on an equal footing with men. The Government of India, meeting a longstanding demand for gender parity in the workforce, has approved an amendment in The Factories Act 1948 to allow women employees to work in nightshifts. The amendment suggests that nightshift for women shall be allowed only if the employer ensures safety, adequate safeguards in the factory as regards occupational safety and health, equal opportunity for women workers, adequate protection of their dignity, honour and transportation from the factory premises to the nearest point of their residence are met. Nightshifts have been in existence for a long time, however for India it was only recently through an amendment to the Factories Act 1948 that it was allowed under the law for women to work nightshifts. Women are participating in almost all the spheres of economic 
activity. From village to city, we can see number of women workers and entrepreneurs contributing towards the national income of the country. Garment units already employ $60 \%$ of women workforce; and with growth in this industry the number this will go up tremendously. So far, the IT sector were employing women for late-night work hours but had no legal obligation to provide the above safety measures. There is no denying the fact that women in India have made a considerable progress in almost seven decades of Independence, but they still have to struggle against many handicaps and social evils in the male-dominated society.

Many evil and masculine forces still prevail in the modern Indian society that resists the forward march of its women folk. With the onset of IT\&BT industry, women work in night shifts. It is the responsibility of the firm to provide office transportation to such employees. Now a days even though the companies provide the facilities for transportation, but the security of the women is not fully ensured as one of the incident occurred in the year 2007 at Pune where a girl working in the call centre was brutally raped by two of her cab drivers assigned by the company, not only this we have come across many of the same incidents in the recent times where the safety of the women cannot be Smart gadget for women safety cannot be fully ensured with the cab facilities provided by the companies.

The only solution to the problem can be taken in a such a way that, women should be assigned with a safety gadget that is portable and ensures her safety. Our project focuses on providing a Smart gadget based on IoT solutions that not only helps to woman escape the critical situations but also ensures safety of the women of the culprit if in case any harassment occurs .

We have proposed a system which helps in such a way that the women wears the gadget or she will have the gadget. Whenever someone is trying to harrash her or someone is following her or she feels unsafely she can press the button on the gadget which she is having. When the button is pressed a message will be sent to the respective persons who is caring her with her current location in the map. The map will get updated based on her current location simultaneously. Also whenever her pulse rate goes high, a message will be sent to the respective persons saying that her condition is abnormal and her current location will be also send to the respective persons.
The existing system is not good that she need to take the phone and call or message the person about her current location and she needs to ask for help. This is not efficient it will take time. The women cannot focus on messaging while she is danger.

So our proposed system solves this problem. Only one click on the button on the gadget will send her location to the respective persons so that she can get help and also an alarm will sound which alerts the nearby persons so that she can get help.

Swami Vivekananda, one of the greatest sons of India, quoted that, "There is no chance for the welfare of the world unless the condition of women is improved, It is not possible for a bird to fly on only one wing." Therefore, the inclusion of "Women Empowerment' as one of the prime goals in the eight Millennium Development Goals underscores the relevance of this fact. Thus, in order to achieve the status of a developed country, India needs to transform its women force into an effective human resource and this is possible only through the empowerment of women.

\section{LITERATURE SURVEY}

The status of women in India has gone through many great changes over the past few thousand years. From equal status with men in ancient times through the low points of the medieval period to the promotion of equal rights by many reformers, the history of women in India has been eventful. In modern India, women have adorned high offices in India including that of the President, Prime Minister, Leader of the Opposition and Speaker of the Lok Sabah. However, women in India continue to face social challenges and are often victims of abuse and violent crimes and, according to a global poll conducted by Thomson Reuters, India is the "fourth most dangerous country" in the world for women, and the worst country for women among the G20 [A group of developing industrial Nations established on 20th August 2003] countries. In India, every day more than 30 women were murdered and many are suffering austere mental and physical trauma. Having this concern in mind many developers have come up with creative applications. Some of such applications are:

\section{She (Society Harnessing Equipment)}

It is a garment embedded with an electronic device. This garment has an electric circuit that can generate $3800 \mathrm{kV}$ which can help the victim to escape. The garment delivers an electric shock to attackers strong enough to cause severe burns, 
protecting the victim from any of the electricity. The development of the garment was made with the capabilities of providing the electric shock when it is squeezed forcefully, so sharing a hug or embrace wouldn't be enough to trigger the voltage

ILA Security The co-founders of this system, have designed three personal alarms that can shock and disorient potential attackers and hence safeguard the victim from perilous situations.

\section{Aeshs (Advanced Electronics System for} Human Safety) Advanced electronics system can be developed that can detect the location and health condition of person, will enable us to take action accordingly. The project will be developed that can detect the location and health condition of a person using electronic gadgets like GPS receiver, GSM, pulse rate sensor, body temperature sensor. The Advanced Electronic System for Human Safety (AESHS) maintains real-time status of all unit elements in the tactical combat zone. The GPS based end-unit is carried by person is connected via Wrist unit to other network sharing units. Implementation of the AESHS can be realized as part of the human monitoring and alarm system (MAS) to provide automatic tracking, monitoring and reporting of individual person.

VithU App VithU, is an emergency App that, at the click of the power button of your smartphone 2 times consecutively begins sending out alert messages every 2 minutes to your contacts that you feed into the app as the designated receivers or guardians. The message says "I am in danger. I need help. Please follow my location." The receiver will receive a link to your location every 2 minutes giving them your updated location. Also, you will get updates on the Crime Scene in India and a "Tips Feed" option exclusively giving you safety tips in an emergency situation. This is an emergency app initiated by a popular Indian crime television series "Gumrah" aired on Channel.

Smart Belt This system is designed with a portable device which resembles a normal belt. It consists of Arduino Board, screaming alarm and pressure sensors. When the threshold of the pressure sensor crosses, the device will be activated automatically. The screaming alarm unit will be activated and send sirens asking help

Aditi Gupta et al., developed to rectify the worries of parents regarding their child security. In this scenario, Our system ensure maximum security and ensures live tracking for their kids because parents worries are genuine. The proposed model that provides the choice to track the location of the children. In case of emergency, children can send a quick message an its current location via SMS. Today smart phones are the basic need of the user today, these smart phones, providing lots of features which make our life so simple and easier. This paper is focused with the safety of children. Today child safety is an important issue across the world as child crime is rapidly growing across the world in this paper we have discussed how a smart phone provides safety and monitoring for the parents so that they can easily track their children according to their requirement.

Akah Moodbidri proposed smart wearable device for children. The purpose of this device is to help parents locate their children. Therefore, the main focus of this paper is to have an SMS text enabled communication medium between the child's wearable and the parent as the environment for GSM mobile communication is almost present everywhere. A device which is used to track the daily activities of the children and find the child using BLUETOOTH and WIFI services. BLUETOOTH is an unreliable medium of communication between the parent and child. The parent can send a text with exact keywords such as "UV,"SOS". If the UV radiation is not suitable for the children, it sends intimation to their parents. It also implemented a SOS light and danger alarm buzzer which is activated by the parents by SMS text should display the SOS signal brightly and sound an alarm which is stopped by SMS.

Bharathi, L et al., proposed system includes a child module and two receiver modules for getting the Information about the missed child on periodical basis. The child module consists of microcontroller, GPS and GSM and the receiver module consist of mobile phone in parent's hand. Main objective of this project is to find out the location of the person who was missed. One more best feature is when ever any guardian or parent sends message to GSM Modem placed in the transmitter which is with the missed child. The location is tracked by the GPS module and these readings are send to the parent or guardian through the GSM at the transmitter. The whole system is integrated in a small chip and attached to the children.

Leonardo D'Errico et al., proposed GPS ,in order to design a solution for parents willing to make certain of their child's following the main steps to school or home, i.e., taking the school bus and entering school or leaving school and entering the school bus. In this paper the applicability of GPS technology efficient capabilities is tested in children tracking and monitoring during their trip 
to and from school by school buses. It enables the cooperation of intelligent system based on IOT, RFID, cloud computing technologies.

It uses the information to alert the parents when child is moving by school bus. It is managed by the backend system when the child enters and exits and school bus. When the child exit from school, taking the school bus and coming home.

Ravi sekhar Yarraboth, presented an android application for the safety of women and activated by a single click this app sends the location URL to the predefined number. The unique feature of this application is send the message tot the predefined number continuously for every five minutes until the stop button is clicked. Location information is used to find the location of the victim immediately. A device which uses $4 \mathrm{G} / 2 \mathrm{G}$ data connection for tracking the location of the sufferer through GPS. It has another module, It can be a registered contacts either police or friends or family which receives the message containing the current location is sent from the sufferer mobile

\section{PROPOSED METHODOLOGY}

We have proposed a women safety device which will help them to send alert messages to their friends ,families when they are in danger. Suppose if a women is in danger, when she clicks the push button, an alert message with her current location will be send to the respective caring persons. Also, when she is not able to press the button and if her pulse rate goes up, an alert message will be automatically send to the respective persons mobile.

If the device got broken, an notification will be send to the women about the device status so, that the device can be repaired or replaced.

\section{METHODOLOGY}

The proposed system is divided into modules for easier implementation.

\section{Modules}

The following is the list of modules:
A. NodeMCU Microcontroller
B. GPS Module
C. Push button Module
D. Pulse Sensor Module
E. Cloud platform

\section{NodeMCU Microcontroller:}

NodeMCU is an open source firmware for which open source prototyping board designs are available. The name "NodeMCU" combines "node" and "MCU" (micro-controller unit). The term "NodeMCU" strictly speaking refers to the firmware rather than the associated development kits.[

Both the firmware and prototyping board designs are open source.

The firmware uses the Lua scripting language. The firmware is based on the Lua project, and built on the Espressif Non-OS SDK for ESP8266. It uses many open source projects, such as lua-cjson and SPIFFS. Due to resource constraints, users need to select the modules relevant for their project and build a firmware tailored to their needs. Support for the 32-bit ESP32 has also been implemented.

The prototyping hardware typically used is a circuit board functioning as a dual in-line package (DIP) which integrates a USB controller with a smaller surface-mounted board containing the MCU and antenna. The choice of the DIP format allows for easy prototyping on breadboards. The design was initially was based on the ESP-12 module of the ESP8266, which is a Wi-Fi SoC integrated with a Tensilica Xtensa LX106 core, widely used in IoT applications.

\section{SENSOR INTERFACE}

In our process, we are using the different sensors ( GPS sensor and Pulse sensor. All the Sensors have a different Pin outs. They are named as a VCC, GND, VOUT. VCC and GND is an supply power of the sensor. Where, VCC connected to the 3.3V of Nodemcu, GND connected to the ground. VOUT is an a output sensing value of the sensor. The ADC on the nodmcu is a 10-bit ADC meaning it has the ability to detect $1,024\left(2^{\wedge} 10\right)$ discrete analog levels.

\section{GPS MODULE:}

The u-blox NEO-6M GPS engine on these modules is quite a good one, and it also has high sensitivity for indoor applications. Furthermore, there's one MS621FE-compatible rechargeable battery for backup and EEPROM for storing configuration settings. The module works well with a DC input in the 3.3- to $5-\mathrm{V}$ range (thanks to its built-in voltage regulator). The VCC and GND pins are connected to the $3.3 \mathrm{v}$ and GND respectively. The Tx pin is connected to the D6 pin of nodemcu and $\mathrm{Rx}$ pin is connected o D7 pin of nodemcu.

\section{Working principle:}

The module is equipped with an HK24C32 two wire serial EEPROM. It is $4 \mathrm{~KB}$ in size and connected to the NEO-6M chip via I2C.The module also contains a rechargeable button battery which acts as a super-capacitor. 
An EEPROM together with battery helps retain the battery backed RAM (BBR). The BBR contains clock data, latest position data(GNSS orbit data) and module configuration. But it's not meant for permanent data storage. As the battery retains clock and last position, time to first fix (TTFF) significantly reduces to $1 \mathrm{~s}$. This allows much faster position locks. Without the battery the GPS always cold-start so the initial GPS lock takes more time. The battery is automatically charged when power is applied and maintains data for up to two weeks without power.

\section{PULSE SENSOR MODULE:}

The non-invasive type of optical heart rate sensor consists of an electronic circuit that monitors heartbeat by clipping onto a finger tip. It does this by shining light into (or through) the finger and measuring how much light is reflected (or absorbed). This goes up and down as blood is pumped through the finger. Usually a clever combination of an infrared light sender and a light receiver is used for the operation.

\section{Working Principle:}

The VCC and GND of the pulse sensor are connected to the power supply of the nodemcu and Vout is used to read analog values from the device. Accordingly, when the pulse goes high, the gps location will be turned on and send to the appropriate person through the cloud platform.

\section{PUSH BUTTON MODULE:}

A push-button (also spelled pushbutton) or simply button is a simple switch mechanism to control some aspect of a machine or a process. Buttons are typically made out of hard material, usually plastic or metal. The surface is usually flat or shaped to accommodate the human finger or hand, so as to be easily depressed or pushed. Buttons are most often biased switches, although many un-biased buttons (due to their physical nature) still require a spring to return to their un-pushed state. Terms for the "pushing" of a buttoninclude pressing, depressing, mashing, s1 apping, hitting, and punching.

\section{Working:}

When the push button is pressed it starts sending location data to the cloud platform .

\section{CLOUD PLATFORM MODULE:}

We are using cloud platforms like thingspeak and ubidots for processing. For sending a message we are using ubidots. Whenever the push button is pressed or pulse goes high message will be send through cloud platform.

The mobile app developers can use this platform to capture the data from the sensors. The sensored data are captured and based on all the sensors critical levels; we could send the data to the cloud. The necessary actions and alerts are configured by multi-level thresholds. Current GPS locations are accessed by satellite signal and messaging services might be preprogrammed to generate the alerts and it sends to the guardians, relations or nearby police stations. By these measures, we could take immediate action. Sample screen of ubidot platform.

To save location data, we are using thing speak which keeps updating the location data accordingly.

\section{CONCLUSION}

This device proposes a Low Cost model which is useful for Women. For future work surveillance feature can be added to avoid intruders for women's. Women's or girls can be monitored by their location and at the right time in order to save cops or police station or friends and family member from men's or intruders or violence. This type of an idea being the first of its kind plays a crucial role towards ensuring Women Safety in the fastest way possible automatically.

\section{REFERENCES}

[1] Harikiran, G. C., Menasinkai, K., \& Shirol, S. (2016). Smart security solution for women based on Internet Of Things(IOT). 2016 International Conference on Electrical, Electronics, and Optimization Techniques (ICEEOT). doi:10.1109/iceeot.2016.7755365

[2] Trisha Sen, Arpita Dutta, Shubham Singh Vaegae Nveen Kumar, "Communication Engineering Proceedings of the Third International Conference on Electronics Communication and Aerospace Technology [ICECA 2019]

[3] Girma Tewolde, Kettering University, USA; SeokJu Lee, Kettering University, USA; Jaerock Kwon, Kettering University, USA IEEE WF-IoT Session: Design and Implementation of Vehicle Tracking System Using GPS/GSM/GPRS Technology 